\title{
Formação inicial de professores e a base de conhecimentos para o ensino de ciências naturais na educação infantil
}

Initial teacher training and the knowledge base for teaching natural sciences in early childhood education

\author{
Raquel de Abreu Fochesato Quidigno ${ }^{1}$ \\ Sérgio Camargo ${ }^{2}$ \\ Tania Teresinha Bruns Zimer ${ }^{3}$
}

\section{Resumo}

Este artigo apresenta uma pesquisa de caráter qualitativo, do tipo documental, realizada no período de 2017 a 2019, que teve como objetivo desvelar o que está manifesto nas estruturas curriculares dos cursos de Licenciatura em Pedagogia em Universidades Públicas Federais, identificando a base de conhecimentos necessários para o Ensino de Ciências Naturais na Educação Infantil. Para tal, foi realizada a análise de Ementas e Planos de Ensino de disciplinas que compõem as estruturas curriculares desses cursos. Assim sendo, primeiramente buscou-se apresentar o contexto em que esta pesquisa está inserida e introduzir as ideias de Shulman (1986, 1987, 2014), Grossman (1990) e Carlsen (2002) sobre os aspectos referentes à constituição da base para o Ensino de Ciências Naturais na Educação Infantil. Ressalta-se que a análise do corpus se fundamenta em elementos da Análise de Conteúdo (BARDIN, 2016). Como resultado do processo de análise dos dados, foram utilizados códigos a priori e 6 códigos emergentes que foram distribuídos em três categorias homônimas dos conhecimentos que constituem a base para o ensino. Portanto, percebeu-se que todos os conhecimentos da base estão presentes nas disciplinas analisadas e, também, foi proposto um modelo para a base de conhecimentos para o Ensino de Ciências na Educação Infantil.

Palavras chave: Pedagogia; Currículo; Educação Infantil; Ensino de Ciências Naturais.

\section{Abstract}

This article presents a qualitative research, from documentary type, carried out in the period from 2017 to 2019, aimed to unveil what is manifested in the curricular structures of the Pedagogy Degree courses at Federal Public Universities, identifying the knowledge base for Teaching Natural Sciences in Early Childhood Education. For this, a course program and teaching plans analysis from some disciplines of these courses were made. Therefore, it was mainly aimed to present the context in which this research is inserted and to introduce the ideas of Shulman (1986, 1987, 2014), Grossman (1990) and Carlsen (2002) on the aspects

\footnotetext{
${ }^{1}$ Universidade Federal do Paraná | raquel.fochesato@gmail.com

${ }^{2}$ Universidade Federal do Paraná | s.camargol@ufpr.br

${ }^{3}$ Universidade Federal do Paraná | taniatbz@ufpr.br
} 
related to the constitution of the basis to teach Natural Sciences in Early Childhood Education. An analysis of the corpus is based on elements of Content Analysis (BARDIN, 2016). As a result of the data analysis process, a priori criteria and 6 emerging codes were used, which were distributed in three homonymous categories of knowledge that qualify the basis for teaching. Thus, it appears that all the knowledge of the base is presented in the analyzed disciplines and, also, a model for the knowledge base for Science Teaching in Early Childhood Education was proposed.

Keywords: Pedagogy; Curriculum; Child Education; Teaching of Natural Sciences.

\section{Introdução}

Os primórdios da Educação Infantil no Brasil datam de aproximadamente final do século XIX, sendo alvo primeiramente do interesse da iniciativa privada. O processo de difusão do atendimento à primeira infância no Brasil ocorreu de duas maneiras, sendo a primeira ocorrendo nos jardins de infância e a segunda, nas creches ou nos asilos. Nesse período histórico havia uma "atribuição do jardim de infância para os ricos, que não poderia ser confundido com os asilos e creches para os pobres" (KUHLMANN JR., 2015, p. 81). Os jardins de infância eram instituições que visavam proporcionar um ensino pré-escolar nos mesmos moldes propostos por Fröbel na Alemanha por volta de 1840. As creches e/ou asilos, por sua vez, eram voltadas ao cuidado, à puericultura, à higiene, a questões assistencialistas, sendo responsáveis pelo atendimento de crianças de mães trabalhadoras.

Ao mesmo tempo que aumentava a demanda por essas instituições de ensino, crescia a demanda de profissionais preparados para atender essas crianças, principalmente nos jardins de infância. Visando o preparo dos profissionais para atuarem com as crianças nas instituições de vertente fröbeliana, inauguram-se algumas Escolas Normais. A primeira delas, no Brasil, foi a Escola Normal Caetano de Campos, em São Paulo (KUHLMANN JR., 2015, 2016). Aqui, percebemos as primeiras iniciativas de uma formação inicial para atender as crianças pequenas, mas ainda uma formação voltada a questões higienistas e de puericultura.

O caráter assistencialista que esteve presente na instituição do atendimento à primeira infância no Brasil permanece até meados do século XX. Nesse período, ainda existe uma expansão dessas instituições (pré-escolas, escolas maternais, jardins de infância e creches) nos diversos estados brasileiros em decorrência da criação de leis e da propagação de instituições sociais (KUHLMAN JR., 2015). No entanto, apesar desse crescimento, não havia uma política específica voltada ao atendimento à primeira infância ou, até mesmo, à formação de professores para atuarem nessa etapa de ensino.

Essa situação mudou em 1932 com uma política nacional sobre o trabalho feminino que exigia a existência de uma creche nos estabelecimentos que empregassem no mínimo 30 mulheres maiores de 16 anos. Partindo dessa política, surgiram outras legislações estaduais sobre a garantia de uma instituição próxima ao local de trabalho para as mães trabalhadoras.

Começam a partir desse período a criação de outras instituições de atendimento à primeira infância, como os parques infantis em São Paulo criados por Mário de Andrade em 1935, a casa da criança, em 1942, e os centros de recreação, em 1960, criados pelo Departamento Nacional da Criança (DNCr), órgão vinculado ao Governo Federal da época (VIEIRA, 1988; KUHLMANN JR., 2016). Nesse contexto histórico, a formação inicial de 
professores para atuar no atendimento à primeira infância da Educação Infantil continuava a ocorrer nas Escolas Normais, conforme determinava a Lei Orgânica do Ensino Normal (BRASIL, 1946), uma vez que o curso de Pedagogia criado no ano de 1939 era destinado à formação de professores para atuação no ensino secundário e normal (BRASIL, 1939).

Na década de 1970, com a consolidação do Regime Militar no Brasil, ocorreu uma mudança de responsabilidades dentro do governo com relação à educação pré-escolar, passando do DNCr para o Ministério da Educação. Nesse período, a pré-escola é percebida pelo governo militar como a solução para os problemas sociais, pois, para eles, ela seria capaz de reduzir os índices de reprovação no ensino primário, apresentando, assim, um caráter compensatório (CAMPOS, ROSEMBERG, FERREIRA, 1993; KUHLMANN JR., 2005). Com relação à formação de professores nesse período, para trabalhar com a primeira infância continua não existindo nenhuma legislação específica sobre a temática.

Com o processo de redemocratização do Brasil, na década de 1980, diversos movimentos sociais colocam em pauta a criação de creches para atender as crianças, uma vez que o número crescente de matrículas nessas instituições de ensino demandava a formulação de políticas que orientassem o trabalho com a primeira infância. O reflexo dessa luta aparecerá na constituição de 1988, onde se preconiza o direito de acesso e permanência das crianças de 0 a 6 anos na creche e na pré-escola (BRASIL, 1988).

O direito à educação para as crianças pequenas será reforçado posteriormente pelo Estatuto da Criança e do Adolescente (ECA) de 1990 e pela Lei de Diretrizes e Bases da Educação Nacional (LDB) de 1996. Documentos e legislações específicas sobre a Educação Infantil, seu currículo, pressupostos e organização foram posteriormente criados. Alguns deles são: os Referenciais Curriculares Nacionais para a Educação Infantil (RCNEI) de 1998, as primeiras Diretrizes Curriculares Nacionais para a Educação Infantil de 1999, as atuais Diretrizes Curriculares Nacionais para a Educação Infantil (DCNEI) de 2009 e a Base Nacional Comum Curricular (BNCC) de 2017.

Desses documentos, ressaltam-se, com relação aos conhecimentos da área de Ciências Naturais a serem trabalhados com a primeira infância, os RCNEl e a BNCC. O primeiro documento elaborado que aborda sobre o currículo voltado à primeira etapa da Educação Básica foram os RCNEl, que tiveram como objetivo auxiliar o professor no seu cotidiano na Educação Infantil. Este documento foi dividido em três volumes: Introdução, Formação pessoal e social e Conhecimento de mundo. Os conhecimentos da área de Ciências Naturais estão inseridos no volume Conhecimento de Mundo, mais especificamente no eixo Natureza e Sociedade, no qual são abordados como trabalhar com os conhecimentos das Ciências Naturais na Educação Infantil buscando orientar a prática do professor (BRASIL, 1998).

Existem diversas críticas com relação à elaboração e instituição desse documento que norteou por muito tempo o ensino na Educação Infantil. A principal delas é com relação à estrutura do documento que apresenta um caráter disciplinar e de certa maneira se torna.

[...] uma proposta de trabalho que rompe com o esforço que tem sido realizado no sentido de construir uma pedagogia para a Educação Infantil que respeite as especificidades do trabalho com crianças menores de 7 anos que frequentam creches e pré-escolas (CERISARA, 1999, p.20).

O ensino de conhecimentos da área de Ciências Naturais só aparece novamente em um documento voltado para a Educação Infantil, elaborado pelo Governo Federal, na versão final da BNCC em 2017. Porém, ao contrário do caráter disciplinar presente nos 
RCNEI, na BNCC os conhecimentos da área das Ciências Naturais aparecem em uma proposta de campos de experiência, que são subordinados aos eixos interações e brincadeira propostos pela DCNEI de 2009. Os cinco campos de experiência devem se comunicar entre si, não devem ser pensados de maneira independente. Salienta-se que os cinco campos de experiência em que as Ciências Naturais estão mais presentes são "espaços, tempos, quantidade, relações e transformações" (BRASIL, 2017).

Somente na LDB de 1996 há, pela primeira vez, a atribuição ao pedagogo para o trabalho na Educação Infantil, exigindo-se a formação mínima em Curso Normal para atuar na primeira etapa da Educação Básica (BRASIL, 1996). Começa-se, então, uma discussão dentro do MEC em conjunto com outros movimentos preocupados com a formação do pedagogo sobre a instituição de novas diretrizes curriculares para o curso de Pedagogia (SCHEIBE, 2007). Dessa forma, passou a englobar também aspectos relacionados à atuação do pedagogo como professor em instituições de atendimento à primeira infância.

Em 2006, é apresentado o parecer do Conselho Nacional de Educação acerca das Diretrizes Curriculares Nacionais para o curso de Licenciatura em Pedagogia, atrelando a identidade do pedagogo à docência (SCHEIBE, 2007; SAVIANI, 2012). Nesse documento existem dois aspectos importantes para o entendimento do desenvolvimento desta pesquisa. Destaque-se que primeiro deles é a determinação do documento sobre o currículo do curso de licenciatura em pedagogia entendendo que este deve

[...] adotar, como referência, o respeito a diferentes concepções teóricas e metodológicas próprias da Pedagogia e àquelas oriundas de áreas de conhecimentos afins, subsidiárias da formação dos educadores, que se qualificam com base na docência da Educação Infantil e dos anos iniciais do Ensino Fundamental (BRASIL, 2006, grifo nosso).

Destaca-se, aqui, a concepção de que a área de Ensino de Ciências pode ser vista como constituinte também do currículo do curso de Licenciatura em Pedagogia como área de conhecimento afim, uma vez que o pedagogo irá trabalhar com conhecimentos da área de Ciências Naturais desde a primeira infância até os anos iniciais do Ensino Fundamental durante a sua atuação como docente. Outro ponto a ser destacado é a vinculação entre o trabalho como professor na Educação Infantil e os subsídios que devem aparecer dentro do currículo, a fim de favorecer a futura atuação profissional do licenciando em Pedagogia.

O segundo aspecto a ser destacado em relação às diretrizes é que o documento destaca algumas incumbências esperadas ao profissional formado no curso de Licenciatura em Pedagogia, dentre elas, "aplicar modos de ensinar diferentes linguagens, Língua Portuguesa, Matemática, Ciências, História, Geografia, Artes, Educação Física, de forma interdisciplinar e adequada às diferentes fases do desenvolvimento humano, particularmente de crianças" (BRASIL, 2006, grifo nosso). Aqui, percebe-se a necessidade de ofertar, ainda na formação inicial, aspectos teóricos e práticos de como trabalhar com os conhecimentos específicos na área de Ciências Naturais com as crianças que frequentam a Educação Infantil.

Partindo do que foi exposto, o artigo tem como objetivo principal desvelar o que está manifesto nas estruturas curriculares dos cursos de Licenciatura em Pedagogia em Universidades Públicas Federais, identificando a base de conhecimentos necessários para o Ensino de Ciências Naturais na Educação Infantil. Na sequência, serão apresentados os resultados da pesquisa iniciada em 2017 e finalizada em 2019, cuja problemática central era compreender quais conhecimentos relacionados à área de Ciências Naturais, ao seu ensino 
e sua aprendizagem estão manifestos nas ementas e nos planos de ensino de cursos de Licenciatura em Pedagogia para a formação dos licenciandos, com vistas à Educação Infantil.

\section{Base de conhecimento para o ensino de ciências}

Para compreender melhor a base de conhecimentos necessária para que o professor seja capaz de ensinar, considerando as especificidades do ensino de conhecimentos da área de Ciências Naturais na Educação Infantil, parte-se das teorias propostas por Shulman (1986, 2014), Grossman (1990) e Carlsen (2002).

Shulman (1986) propõe, partindo de suas inquietações acerca de como os professores constituíam os conhecimentos utilizados para o exercício do magistério, sete categorias mínimas de conhecimentos que o professor deve ter para ensinar. Seriam elas:

conhecimento do conteúdo; conhecimento pedagógico geral, com especial referência aos princípios e estratégias mais abrangentes de gerenciamento e organização de sala de aula, que parecem transcender a matéria; conhecimento do currículo, particularmente dos materiais e programas que servem como "ferramentas do ofício" para os professores; conhecimento pedagógico do conteúdo, essa amálgama especial de conteúdo e pedagogia que é o terreno exclusivo dos professores, seu meio especial de compreensão profissional; conhecimento do aluno e de suas características; conhecimento de contextos educacionais, desde o funcionamento do grupo ou sala de aula, passando pela gestão e financiamento dos sistemas educacionais, até as características das comunidades e suas culturas; e conhecimento dos fins, propósitos e valores da educação e de sua base histórica (adaptado de SHULMAN, 2014, p. 206).

Apesar de inicialmente propor sete conhecimentos, Shulman (1986) apontou que esses sete podem ser resumidos em três principais conhecimentos: o conhecimento do conteúdo específico, o conhecimento pedagógico geral e o conhecimento pedagógico do conteúdo seriam os componentes da base de conhecimentos para o ensino (MIZUKAMI, 2014).

O conhecimento do conteúdo específico pode ser definido como as compreensões, saberes, informações de uma área de conhecimento específica, bem como como essa determinada área se constituiu e consolidou. Esse conhecimento pode ser dividido em dois conhecimentos: sintático e substantivo, sendo o sintático definido como a maneira como a área específica do conhecimento se construiu e como ela determina e verifica novos conhecimentos. Já o substantivo possui em sua estrutura os "paradigmas explicativos utilizados pela área" (MIZUKAMI, 2004, p. 38).

O conhecimento pedagógico geral, por sua vez, será aquele relacionado às noções básicas de como ensinar, englobando aspectos como o ensino e a aprendizagem, a gestão escolar, conhecimentos interdisciplinares, a didática, a organização escolar, entre outros, ou seja, conhecer elementos do domínio pedagógico sobre os princípios gerais de como ensinar.

O terceiro constituinte da base proposta por Shulman $(1986,2014)$ é o conhecimento pedagógico do conteúdo, que pode ser definido como aquele específico do professor, ou seja, trata-se de um conhecimento que difere dos especialistas e tem como protagonista o 
profissional docente. Pode ser visto como uma combinação entre os dois conhecimentos anteriores (o do conteúdo e o pedagógico geral), e será por meio desse tipo de conhecimento que o professor irá mediar a construção de saberes do seu aluno partindo de um conteúdo específico.

Segundo Shulman (2014), a base de conhecimentos de ensino pode ser construída ao longo da carreira do professor partindo de quatro fontes: a formação acadêmica, pelo ambiente escolar e as características que o compõem, por pesquisas que afetem diretamente a prática docente e a própria prática do professor. Nesta pesquisa, o foco de análise são as ementas e os planos de ensino das disciplinas que abordam o Ensino de Ciências Naturais na formação inicial do Pedagogo visando sua atuação na Educação Infantil. Dessa maneira, busca-se analisar uma das fontes que contribuem à constituição dessa base de conhecimentos para o ensino, que é a formação acadêmica.

No intuito de complementar a base de conhecimentos para o ensino de Shulman (1986, 2014), a autora Grossman (1990) propõe uma síntese em quatro conhecimentos, acrescentando à síntese de Shulman $(1986,2014)$ o conhecimento do contexto. Outra modificação sugerida pela autora seria a de mudar a nomenclatura de "conhecimento do conteúdo" para "conhecimento do tema", a fim de melhor expressar as ideias originais de Shulman (FERNANDEZ, 2014, 2015). Grossman (1990) acrescenta a sua proposta sugestões de quais seriam os componentes de cada um desses conhecimentos que constituem a base. A síntese da autora pode ser vista na figura 1:

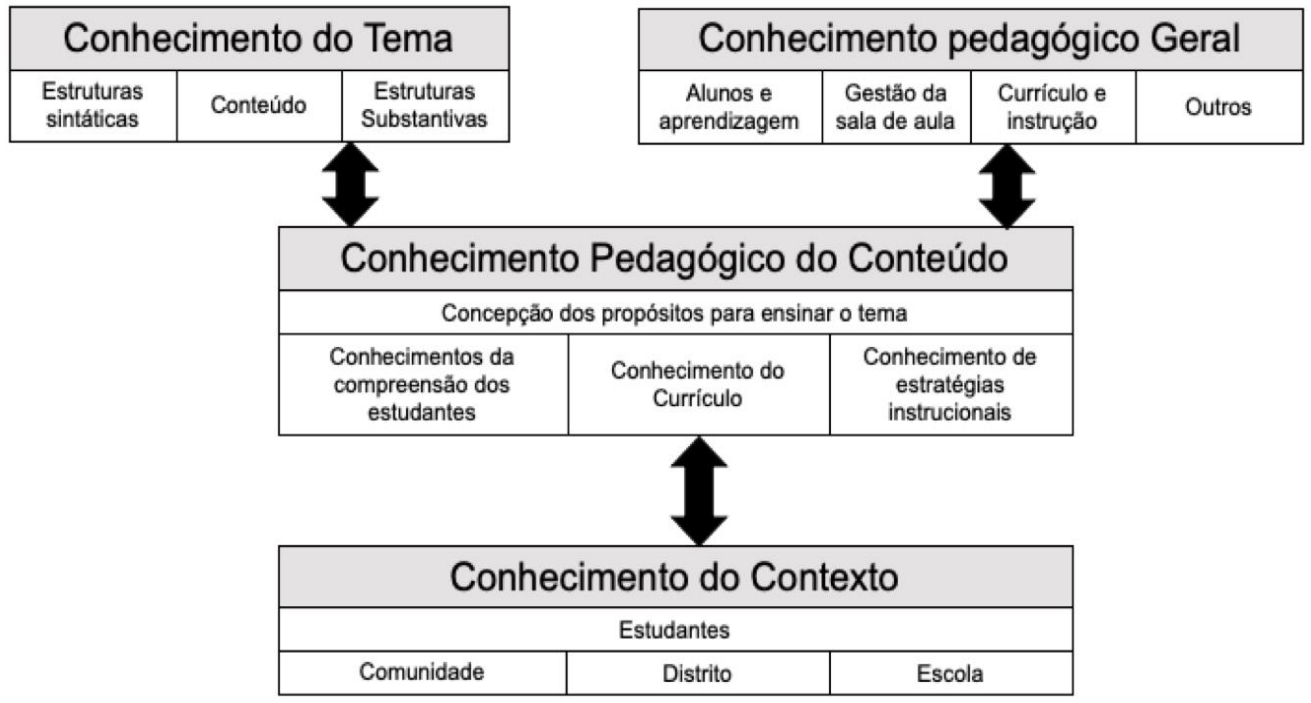

Figura 1 - Modelo de Conhecimento de Professores. Fonte: Grossman (1990, p.5, tradução nossa)

Partindo do modelo proposto por Shulman (1986, 2014), bem como o de Grossman (1990), outros autores, como Carlsen (2002), buscaram adaptar o modelo para o professor que ensina Ciências Naturais. Carlsen (2002) parte do modelo adaptado por Grossman para propor um modelo que seria específico para o professor de Ciências Naturais.

Nesse modelo, Carlsen (2002), modifica o entendimento sobre o contexto. Para o autor, o contexto deixará de ser um tipo de conhecimento separado e passa a ser visto como pano de fundo presente em toda a base. Portanto, o conhecimento do contexto estará presente nos demais como componente (FERNANDEZ, 2015). Tal característica pode melhor ser observada na figura 2. 


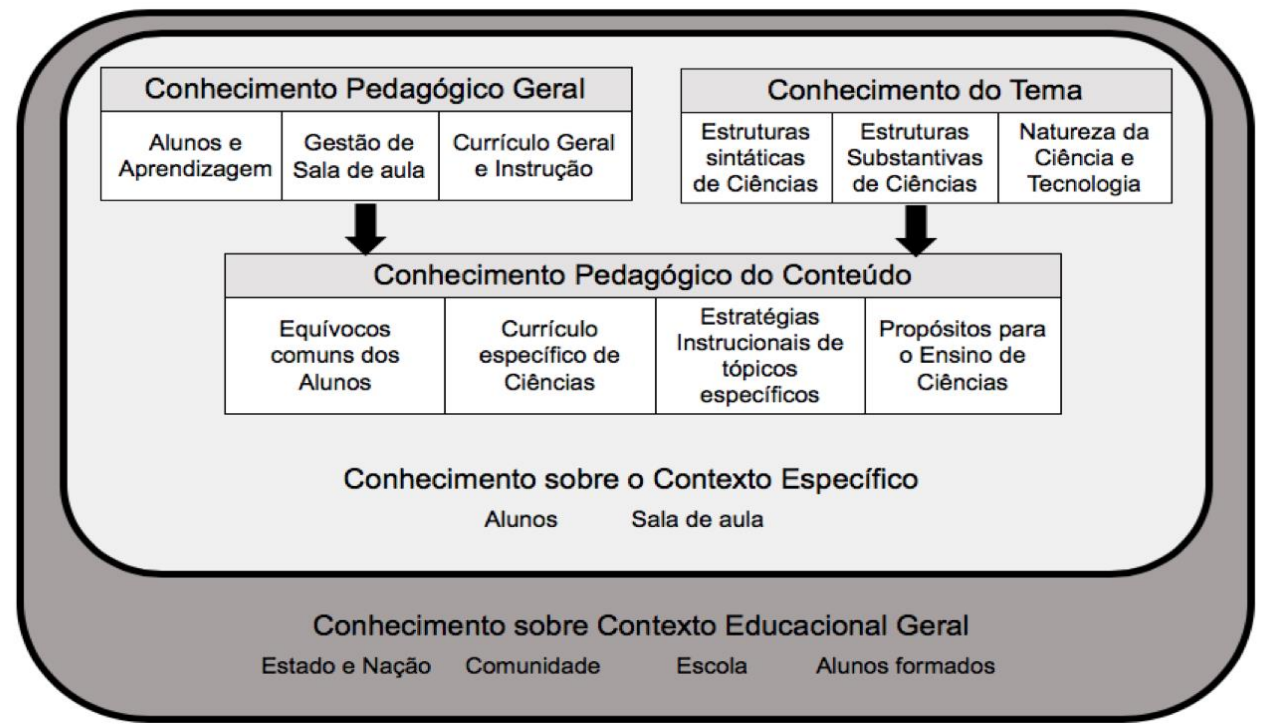

Figura 2 - Modelo de Conhecimento de Professores. Fonte: Grossman (2002, p.136, tradução nossa)

Outra modificação presente no modelo apresentado na figura 2, comparando com as propostas de Shulman (1986, 2014) e de Grossman (1990), é a relação entre os conhecimentos. Para Carlsen (2002), existe uma relação de hierarquia entre eles (FERNANDEZ, 2014, 2015). Aqui, o conhecimento pedagógico do conteúdo passa a ser visto como dependente do conhecimento pedagógico do tema e do conhecimento pedagógico geral. No entanto, o contrário não é verdadeiro, pois não existe dependência entre o conhecimento do tema e o pedagógico geral para com o conhecimento pedagógico do conteúdo.

Para o conhecimento pedagógico geral, Carlsen (2002) apresenta os mesmos domínios propostos por Grossman (1990). Tais domínios refletem a ideia original de Shulman (1986, 2014) de que esse conhecimento é composto por aspectos pedagógicos fundamentais para o professor exercer sua função em sala de aula.

O conhecimento do tema englobaria em seus domínios os aspectos específicos da disciplina, desde o início da constituição da área, sua consolidação, passando pelos conteúdos por ela tratados e abordando suas problemáticas. Esses dois aspectos, tanto das estruturas substantivas quanto das sintáticas, já haviam sido apontadas por Shulman (1986). O modelo proposto, no entanto, busca reforçar esses aspectos ao adicionar a questão da natureza da ciência e da tecnologia (CARLSEN, 2002), pretendendo, assim, que os futuros professores que ensinarão Ciências Naturais gerem entendimentos sobre a ciência e a tecnologia, "criando experiências científicas sociologicamente autênticas" (CARLSEN, 2002, p. 140-141, tradução nossa).

O terceiro conhecimento (o pedagógico do conteúdo), para Carlsen (2002), deveria englobar a compreensão dos equívocos comuns dos alunos e as estratégias instrucionais de tópicos específicos do conteúdo, o que complementaria as questões metodológicas apontadas por Grossman (1990). Por meio do incremento desses dois domínios, principalmente aquele que considera as estratégias, existe a inserção da habilidade dos professores para tomar decisões sobre a melhor maneira de se trabalhar com determinado conteúdo, gerenciar as aulas de laboratório, realizar as explicações, entre outras questões importantes em sala de aula. 


\section{O caminho trilhado na pesquisa}

Esta pesquisa, em relação a sua natureza, fundamenta-se em uma abordagem qualitativa e tem como procedimentos a pesquisa documental. Optou-se pelo uso da pesquisa documental, uma vez que o corpus que a compõe seria formado pelas ementas e planos de ensino de disciplinas que abordam o Ensino de Ciências Naturais nos cursos de Licenciatura em Pedagogia das Universidades Federais Brasileiras. Assim, percebe-se aqui que a pesquisa documental pode ser também uma maneira de obter novas informações e dados sobre a problemática de pesquisa, como se pretende mostrar neste estudo.

A pesquisa documental, assim como outros procedimentos relativos à pesquisa qualitativa, possui um caminho a ser trilhado pelo pesquisador. Com relação a esse caminho, existe certo consenso entre diferentes autores sobre quais seriam as etapas de uma pesquisa com essa escolha metodológica (LÜDKE e ANDRÉ, 2017).

\section{Primeira etapa: seleção e caracterização dos documentos}

Na primeira etapa foi realizada a seleção e caracterização dos documentos que constituíram o corpus da pesquisa. Neste caso, primeiramente realizou-se um levantamento das Universidades Federais (U.F.) brasileiras que ofertam o curso de Licenciatura em Pedagogia presencial. Ressalta-se que no período de realização da pesquisa, o Brasil contava com 63 U.F., sendo que 52 ofertavam o curso de Licenciatura em Pedagogia, cerca de $83 \%$ do total.

Após localizar as instituições, realizou-se uma busca online referente à estrutura curricular de cada um desses cursos. Cabe ressaltar aqui que todas as estruturas curriculares para o curso de Pedagogia em todas as instituições estavam disponíveis para amplo acesso. Com isso, foram encontradas 93 estruturas curriculares nas 52 U.F. Esse número discrepante ocorreu pelo fato de algumas dessas instituições ofertarem o curso de Pedagogia em diferentes campus, que possuíam estruturas e disciplinas diferentes entre si.

Partindo desse levantamento primário, foram selecionadas pelo nome as disciplinas que abordavam o tópico Ensino de Ciências Naturais. Observou-se, por essa análise primária, que existe uma grande variação entre nomes das disciplinas, cargas-horárias delas e do curso como um todo. Foi possível constatar ainda que a maior parte dos cursos de Pedagogia, selecionados neste primeiro momento, reservava menos de $5 \%$ de sua cargahorária total para disciplinas relacionadas ao Ensino de Ciências Naturais.

\begin{tabular}{|l|c|c|c|c|}
\hline \multicolumn{2}{|c|}{ Quadro 1-Relação de planos de Ensino por região. Fonte: Os autores. } \\
\hline Região & U.F. & $\begin{array}{l}\text { U.F que oferta o } \\
\text { curso presencial } \\
\text { de Pedagogia }\end{array}$ & $\begin{array}{l}\text { U.F. que } \\
\text { disponibilizaram os } \\
\text { Planos de Ensino }\end{array}$ & $\begin{array}{l}\text { Planos de Ensino } \\
\text { obtidos online e } \\
\text { via e-mail }\end{array}$ \\
\hline Centro-oeste & 5 & 5 & 2 & 5 \\
\hline Nordeste & 18 & 14 & 2 & 6 \\
\hline Norte & 10 & 9 & 2 & 15 \\
\hline Sudoeste & 19 & 16 & 9 & 4 \\
\hline Sul & 11 & 8 & 3 & 36 \\
\hline TOTAL & 63 & 52 & 18 & 6 \\
\hline
\end{tabular}

Após essa seleção, buscou-se as ementas dessas disciplinas. Dentre as 52 U.F. selecionadas, apenas 5 não disponibilizaram online suas ementas e 3 não a disponibilizaram 
em pelo menos um dos campus. Realizou-se, ainda, primeiramente de maneira online e depois via e-mail, a busca dos planos de ensino das disciplinas selecionadas. A sistematização das contribuições obtidas online e recebidas via e-mail encontram-se no Quadro 1.

Observando o Quadro 1, é possível perceber que cerca de 35\% das U.F. disponibilizaram os planos de ensino, seja de maneira online ou via e-mail. É possível observar ainda uma divergência entre o número de universidades que disponibilizaram os planos de ensino e o total de planos obtidos das disciplinas que abordavam o Ensino de Ciências Naturais. Isso ocorre, pois, em alguns casos, uma mesma universidade oferta mais de um curso de Pedagogia em diferentes campus. Outro fator que altera esses dados é a presença, em um mesmo curso, de mais de uma disciplina que aborda o Ensino de Ciências.

\section{Segunda etapa: avaliação crítica}

Estando em posse de todos os documentos que constituíram o corpus da pesquisa, passa-se para a próxima etapa da pesquisa documental, denominada avaliação crítica (CELLARD, 2008). Nessa etapa, considera-se o contexto em que esse documento foi elaborado, bem como a sua autenticidade, autoria, sua natureza, seus conceitos-chave e sua lógica interna.

Passa-se, então, para a análise dos dados presentes nos documentos propriamente dita. Para essa etapa, utiliza-se usualmente como método a Análise de Conteúdo (LÜDKE e ANDRÉ, 2017). Nesta pesquisa foi utilizada a Análise de Conteúdo pelo viés de Bardin (2016) com o auxílio do software ATLAS.ti ${ }^{4}$. Partindo dos quatro pilares da Análise de Conteúdo (a pré-análise, a exploração do material, o tratamento dos resultados, a inferência e a interpretação), iniciou-se a última etapa da pesquisa documental.

Quadro 2 - Relação da distribuição do corpus da pesquisa por região. Fonte: Os autores.

\begin{tabular}{|l|c|c|c|c|c|}
\hline Região & $\begin{array}{l}\text { U.F que oferta o } \\
\text { curso presencial de } \\
\text { Pedagogia }\end{array}$ & $\begin{array}{l}\text { U.F que } \\
\text { forneceram } \\
\text { as Ementas }\end{array}$ & $\begin{array}{l}\text { Total de } \\
\text { Ementas } \\
\text { obtidas }\end{array}$ & $\begin{array}{l}\text { U.F. que } \\
\text { disponibilizara } \\
\text { m os P. E. }\end{array}$ & $\begin{array}{l}\text { Total } \\
\text { de } \\
\text { P.E. }\end{array}$ \\
\hline Centro-oeste & 5 & 4 & 6 & 2 & 5 \\
\hline Nordeste & 14 & 14 & 41 & 1 & 2 \\
\hline Norte & 9 & 9 & 43 & 2 & 5 \\
\hline Sudoeste & 16 & 15 & 32 & 9 & 14 \\
\hline Sul & 8 & 6 & 8 & 2 & 3 \\
\hline TOTAL & 52 & 48 & 130 & 16 & 29 \\
\hline
\end{tabular}

Na etapa de pré-análise, houve a organização e sistematização de dados utilizando as ferramentas disponíveis no software ATLAS.ti, sendo realizada nessa etapa a leitura flutuante das ementas e planos de ensino obtidos e a seleção de quais documentos iriam compor efetivamente o corpus da pesquisa. Foram descartadas as U.F. que não disponibilizaram as ementas e/ou que nos planos de ensino (P.E.) não constavam a ementa, conteúdo

\footnotetext{
${ }^{4}$ O software ATLAS.ti é um programa que auxilia o pesquisador na análise de dados qualitativos. Trata-se de uma ferramenta que facilita a sistematização dos dados. Tal software foi utilizado com a licença educacional para usuário único.
} 
programático e as referências. Após essa seleção, restaram 130 ementas de um total de 155 disciplinas e 29 planos de ensino de um total de 36 disciplinas. A distribuição dessa amostra representativa, pertinente e homogênea, pode ser vista na Quadro 2.

Após esse levantamento e da sistematização dos dados, passou-se para a observação de indicadores que auxiliaram na identificação dos conhecimentos constituintes da base para o Ensino de Ciências Naturais para a Educação Infantil. Para isso, foram utilizadas como indicadores as dimensões que compõem os três tipos de conhecimento (pedagógico geral, do tema e pedagógico do conteúdo), segundo Carlsen (2002). Os indicadores utilizados foram: alunos e aprendizagem, gestão de sala de aula, currículo geral e instrução, estruturas sintáticas de Ciências, estruturas substantivas de Ciências, natureza e tecnologia, equívocos comuns dos alunos, currículo específico de Ciências, estratégias instrucionais de tópicos específicos, propósitos para o Ensino de Ciências. A definição de cada um dos indicadores pode ser vista na Quadro 3.

Quadro 3 - Definição indicadores utilizados na unitarização. Fonte: Os autores.

\begin{tabular}{|c|c|}
\hline INDICADOR & DEFINIÇÃO \\
\hline $\begin{array}{l}\text { Alunos e } \\
\text { Aprendizagem }\end{array}$ & $\begin{array}{l}\text { Indicador relacionado à abordagem nas disciplinas sobre a } \\
\text { maneira como os alunos aprendem, como ocorrem seus } \\
\text { processos de desenvolvimento, possíveis dificuldades de } \\
\text { aprendizagem e outros pontos sobre a construção do } \\
\text { conhecimento por parte do aluno. }\end{array}$ \\
\hline $\begin{array}{l}\text { Currículo } \\
\text { Ciências }\end{array}$ & $\begin{array}{l}\text { Indicador que verifica a maneira como o componente curricular } \\
\text { Ciências Naturais aparece no currículo geral. }\end{array}$ \\
\hline $\begin{array}{l}\text { Currículo geral e } \\
\text { instrução }\end{array}$ & $\begin{array}{l}\text { Indicador que verifica a presença ou não de aspectos } \\
\text { relacionados ao currículo, legislações e diretrizes vigentes que } \\
\text { orientam o professor em sua prática em sala. }\end{array}$ \\
\hline $\begin{array}{l}\text { Equívocos comuns dos } \\
\text { alunos }\end{array}$ & $\begin{array}{l}\text { Indicador que aponta o trabalho com as possíveis dificuldades } \\
\text { dos alunos com alguns temas e assuntos relacionados à área de } \\
\text { Ciências Naturais. }\end{array}$ \\
\hline $\begin{array}{l}\text { as } \\
\text { hais de } \\
\text { específicos }\end{array}$ & $\begin{array}{l}\text { dicador relacionado à abordagem de diferentes metodologias e } \\
\text { stratégias para se ensinar Ciências. }\end{array}$ \\
\hline $\begin{array}{l}\text { Estruturas sintáticas de } \\
\text { Ciências }\end{array}$ & $\begin{array}{l}\text { Indicador que expressa como a disciplina e a área de Ciências } \\
\text { Naturais se constituiu, bem como os processos que essa área } \\
\text { utiliza, para validar os novos conhecimentos que a compõem. }\end{array}$ \\
\hline $\begin{array}{l}\text { Estruturas substantivas } \\
\text { de Ciências }\end{array}$ & $\begin{array}{l}\text { Indicador que é característico pela presença da apresentação da } \\
\text { essência da área de Ciências Naturais, pelos paradigmas } \\
\text { explicativos utilizados pela área. }\end{array}$ \\
\hline Gestão de sala de aula & $\begin{array}{l}\text { Indicador atribuído a segmentos que apontam o trabalho com } \\
\text { aspectos necessários para o gerenciamento de uma sala de aula, } \\
\text { desde o planejamento, até aprender as maneiras possíveis para } \\
\text { lidar com situações de tensão no ambiente escolar. }\end{array}$ \\
\hline $\begin{array}{l}\text { Natureza da Ciências e } \\
\text { Tecnologia }\end{array}$ & $\begin{array}{l}\text { Indicador relacionado à existência de elementos que apontem } \\
\text { para a vivência de experiências científicas sociologicamente } \\
\text { autênticas sobre as Tecnologias e as Ciências Naturais, } \\
\text { percebendo, assim, a conexão desses dois aspectos com o } \\
\text { cotidiano. }\end{array}$ \\
\hline $\begin{array}{l}\text { Propósitos para o } \\
\text { ensino de Ciências }\end{array}$ & $\begin{array}{l}\text { Indicador atribuído a trechos que manifestavam a preocupação } \\
\text { em expor os motivos e a importância de se ensinar Ciências } \\
\text { Naturais. }\end{array}$ \\
\hline
\end{tabular}


Para cada um dos indicadores aqui apresentados, foram criados códigos de mesma nomenclatura no software ATLAS.ti, a fim de serem utilizados na próxima etapa de análise (a exploração do material). Houve ainda o cuidado em nomear os documentos de maneira a facilitar a análise. Para isso, os planos de ensino receberam o nome "P.E. - U.F. X.Y", em que $X$ representa o número atribuído à universidade e $Y$ o número atribuído a um determinado campus que ofertava o curso de Licenciatura em Pedagogia. A mesma maneira de codificação foi utilizada com as ementas apenas modificando o P.E. por E., ficando da seguinte maneira "E. - U.F. X.Y".

Iniciou-se, assim, a próxima etapa da Análise de Conteúdo, que é a exploração do material (BARDIN, 2016). Nesta etapa, primeiramente, optou-se por analisar os documentos que apresentavam alguma menção ao Ensino de Ciências Naturais na Educação Infantil. Para isso, foi utilizada a ferramenta do software ATLAS.ti denominada auto-codiging ${ }^{5}$. Utilizando tal ferramenta, foram realizadas duas buscas, uma nas ementas e outra nos planos de ensino, com as palavras "infantil", "infância" e "criança".

Para a realização dessa busca, foram criados dois códigos "Educação Infantil - Ementas" e "Educação Infantil - P.E.", atribuídos respectivamente a trechos das ementas e dos planos de ensino que apresentavam relação com a Educação Infantil. Partindo dessa busca, foram selecionados no software ATLAS.ti um total de 32 ementas e 13 planos de ensino, distribuídos entre as diferentes regiões brasileiras, como pode ser observado no Quadro 4.

Quadro 4 - Relação da distribuição por região das ementas e planos de ensino selecionados para a análise. Fonte: Os autores.

\begin{tabular}{|l|l|l|l|l|l|}
\hline Região & $\begin{array}{l}\text { U.F que oferta } \\
\text { o curso } \\
\text { presencial de } \\
\text { Pedagogia }\end{array}$ & $\begin{array}{l}\text { U.F com } \\
\text { Ementas } \\
\text { selecionadas }\end{array}$ & $\begin{array}{l}\text { Total de } \\
\text { Ementas } \\
\text { selecionadas }\end{array}$ & $\begin{array}{l}\text { U.F. com P. } \\
\text { E. } \\
\text { selecionado } \\
\text { S }\end{array}$ & $\begin{array}{l}\text { Total de P.E. } \\
\text { selecionados }\end{array}$ \\
\hline Centro-oeste & 5 & 2 & 2 & 2 & 2 \\
\hline Nordeste & 14 & 5 & 7 & 0 & 0 \\
\hline Norte & 9 & 3 & 6 & 1 & 1 \\
\hline Sudoeste & 16 & 8 & 12 & 6 & 9 \\
\hline Sul & 8 & 4 & 5 & 1 & 1 \\
\hline TOTAL & 52 & 22 & 32 & 10 & 13 \\
\hline
\end{tabular}

Como pode ser visualizado no Quadro 4, apenas a região nordeste não teve representação quanto aos planos de ensino analisados, uma vez que os documentos selecionados não apresentavam relação com o ensino de Ciências Naturais da Educação Infantil. Foram obtidos, assim, um total de 89 excertos, sendo 45 provenientes das 22 ementas selecionadas e 44 trechos dos 13 planos de ensino. Levando em consideração o corpus primário da pesquisa, 130 ementas e 29 planos de ensino e o total de trechos encontrados, pode-se afirmar que existem indícios de um possível déficit na formação dos futuros professores que irão trabalhar com a primeira etapa da Educação Básica.

Após a pesquisa e seleção dos trechos que mencionavam a Educação Infantil, houve a releitura de cada um dos excertos. Nesse processo, foram utilizados os códigos, gerados

\footnotetext{
${ }^{5}$ Auto-coding é o nome de uma ferramenta do software ATLAS.ti que permite realizar uma busca automática por palavra-chave dentro dos documentos inseridos no programa.
} 
partindo dos indicadores e criados na etapa anterior do processo de Análise de Conteúdo. Esses códigos foram inseridos dentro do software ATLAS.ti para facilitar o processo de codificação dos trechos selecionados dos documentos constituintes do corpus da pesquisa (ementas e planos de ensino).

Durante o processo de codificação, houve a necessidade de criar três novos códigos: Ensino na Educação Infantil, Pesquisa em Educação e em Ensino de Ciências, Histórico do Ensino de Ciências. Tais códigos emergiram dos dados, ou seja, foram criados a posteriori, considerando as especificidades das informações manifestas neles e que não estavam englobadas nos códigos listados a priori.

O código "Ensino na Educação Infantil" foi utilizado em trechos que apresentavam relação com aspectos específicos do trabalho com a primeira infância, o currículo da Educação Infantil, cuidado aliado à educação, concepções de infância e a história da Educação Infantil no Brasil. Já o código "Pesquisa em Educação e em Ensino de Ciências" foi atribuído a excertos que mencionavam a pesquisa como componente na formação do licenciado, seja por análises de pesquisa da área, seja por abordar as tendências dentro da área de Ensino Ciências. O código "Histórico do Ensino de Ciências" é atribuído aos trechos que abordaram a constituição, consolidação e evolução da área de Ensino de Ciências.

Dessa maneira, foram obtidos um total 89 trechos, codificados 256 vezes, considerando os planos de ensino e as ementas. $O$ total de codificações foi superior ao total de trechos selecionados devido à atribuição de mais de um código para um mesmo trecho. Os códigos "estratégias instrucionais de tópicos específicos" e "alunos e aprendizagem" estavam presentes em cerca de 59\% nas ementas dos trechos analisados e $57 \%$ dos excertos nos planos de ensino. Esses códigos estão relacionados, respectivamente, ao conhecimento pedagógico do conteúdo e ao conhecimento geral do conteúdo, o que pode indicar um enfoque maior nesses conhecimentos quando observamos a formação do pedagogo para o ensino dos aspectos relativos à área de Ciências Naturais na Educação Infantil.

Observou-se, ainda, que o aparecimento do código "estruturas sintáticas das Ciências" apareceu nos mesmos trechos em que foi atribuído o código "estruturas substantivas das Ciências". Tal aspecto pode indicar uma abordagem conjunta sobre a constituição da área de Ciências Naturais e dos seus paradigmas explicativos.

Apesar desses dados se mostrarem importantes para compreender quais conhecimentos relacionados à área de Ciências Naturais, ao seu ensino e sua aprendizagem, com vistas à Educação Infantil, optou-se por analisar as ementas selecionadas em sua integralidade e nos planos de Ensino, selecionando as ementas, conteúdos programáticos e as referências que os compõem. Nessa análise mais geral, foram considerados, também, os trechos codificados na etapa anterior, salientando que os trechos selecionados foram as frases que constituíam os textos dos documentos selecionados para análise. Dessa maneira, obteve-se um total de 444 excertos, sendo 161 das ementas isoladas e 283 dos planos de ensino. Para essa nova análise, após nova leitura flutuante dos trechos, houve a necessidade da criação de mais três novos códigos.

O primeiro deles foi o "Ensino de Ciências em Espaços não formais", o qual englobou trechos que apresentaram a abordagem de questões referentes ao Ensino de Ciências em locais diferentes da escola e as características do ensino nesses ambientes. Já o código "Inclusão no Ensino de Ciências" foi atribuído a excertos que manifestavam a preocupação específica com os aspectos relacionados à inclusão voltada ao Ensino de Ciências Naturais, como, por exemplo, a criação de materiais didáticos. O último código criado foi o 
"Interdisciplinaridade", que foi utilizado para codificar trechos que apontavam para a necessidade do Ensino de Ciências Naturais relacionado a outras áreas do conhecimento. 0 Quadro 5 apresenta as informações relativas ao processo de codificação.

Quadro 5 Codificação dos indicadores das ementas e planos de ensino. Fonte: Os autores.

\begin{tabular}{|l|c|c|c|}
\hline INDICADOR & $\begin{array}{c}\text { TOTAL DE } \\
\text { CÓDIGOS- } \\
\text { EMENTAS }\end{array}$ & $\begin{array}{c}\text { TOTAL DE } \\
\text { CÓDIGOS - P.E. }\end{array}$ & TOTAL \\
\hline Alunos e Aprendizagem & $59(13,05 \%)$ & $105(16,33 \%)$ & $164(14,98 \%)$ \\
\hline Currículo específico de Ciências & $55(12,17 \%)$ & $66(10,26 \%)$ & $121(11,05 \%)$ \\
\hline Currículo geral e instrução & $44(9,73 \%)$ & $36(5,6 \%)$ & $80(7,31 \%)$ \\
\hline Ensino de Ciências em Espaços não-formais & $3(0,66 \%)$ & $7(1,09 \%)$ & $10(0,91 \%)$ \\
\hline Ensino na Educação Infantil & $4(0,88 \%)$ & $10(1,56 \%)$ & $14(1,28 \%)$ \\
\hline Equívocos comuns dos alunos & $12(2,65 \%)$ & $20(3,11 \%)$ & $32(2,92 \%)$ \\
\hline Estratégias instruc. de tópicos específicos & $71(15,71 \%)$ & $123(19,13 \%)$ & $194(17,72 \%)$ \\
\hline Estruturas sintáticas de Ciências & $44(9,73 \%)$ & $56(8,71 \%)$ & $100(9,13 \%)$ \\
\hline Estruturas substantivas de Ciências & $44(9,73 \%)$ & $56(8,71 \%)$ & $100(9,13 \%)$ \\
\hline Gestão de sala de aula & $35(7,74 \%)$ & $48(7,47 \%)$ & $83(7,58 \%)$ \\
\hline Histórico do Ensino de Ciências & $10(2,21 \%)$ & $20(3,11 \%)$ & $30(2,27 \%)$ \\
\hline Inclusão no Ensino de Ciências & $2(0,44 \%)$ & $6(0,93 \%)$ & $8(0,73 \%)$ \\
\hline Interdisciplinaridade & $9(1,99 \%)$ & $8(1,24 \%)$ & $17(1,55 \%)$ \\
\hline Natureza da Ciências e Tecnologia & $32(7,08 \%)$ & $34(5,29 \%)$ & $66(6,03 \%)$ \\
\hline Pesquisa em Ensino de Ciências & $8(1,77 \%)$ & $9(1,40 \%)$ & $17(1,55 \%)$ \\
\hline Propósitos para o Ensino de Ciências & $20(4,42 \%)$ & $39(6,07 \%)$ & $59(5,39 \%)$ \\
\hline TOTAL & $452(100 \%)$ & $643(100 \%)$ & $1095(100 \%)$ \\
\hline
\end{tabular}

Cabe ressaltar aqui que o total de códigos atribuídos foi superior ao número de trechos selecionados, uma vez que, em um mesmo excerto, houve a presença de mais de uma dimensão. O Quadro 5 apresenta dois valores. Os valores absolutos correspondem à quantidade de códigos atribuídos e os valores em porcentagem expressam a proporção do aparecimento de determinado código quando comparado com o total de códigos atribuídos aos trechos analisados. Após o término do processo de unitarização e codificação do material, partiu-se para a etapa de categorização.

Levando em consideração o objetivo proposto, foram estabelecidas as categorias definidas a priori partindo das teorias de Shulman $(1986,1987,2014)$ e Carlsen (2002). Como categorias, foram utilizados os conhecimentos constituintes da base para o Ensino de Ciências Naturais: o conhecimento do tema, o conhecimento pedagógico geral e o conhecimento pedagógico do conteúdo. Os códigos utilizados na etapa anterior seriam as dimensões constituintes de cada um desses conhecimentos e, consequentemente, de cada uma dessas categorias.

Os códigos emergentes "Interdisciplinaridade" e "Ensino na Educação Infantil" foram inseridos como dimensões das categorias conhecimento pedagógico geral, uma vez que essa categoria engloba os conhecimentos específicos da área pedagógica que subsidiam o professor para compreender o processo de ensino-aprendizagem. Já os códigos "Ensino de Ciências em Espaços não formais", "Inclusão no Ensino de Ciências", "Pesquisa em Ensino de Ciências" e "Histórico do Ensino de Ciências" constituem as dimensões que compõem a categoria conhecimento pedagógico do conteúdo, a qual abrange questões sobre os aspectos específicos para que o professor ensine Ciências Naturais. A categoria 
conhecimento do tema, que abrange os trechos que tratam de questões da constituição, abordagem e das especificidades da área das Ciências Naturais, não teve dimensões emergentes adicionadas.

Durante o processo de categorização, foi observada a existência de, pelo menos, uma dimensão de cada categoria em todas as disciplinas analisadas, tornando possível afirmar que existe a abordagem de todos os conhecimentos, mesmo que de maneiras diferentes, nos documentos analisados. No Quadro 6, a seguir, é possível observar a distribuição total de códigos por categoria.

Quadro 6 - Relação entre as categorias e quantidades de códigos atribuídos. Fonte: Os autores.

\begin{tabular}{|l|c|c|c|}
\hline \multicolumn{1}{|c|}{ CATEGORIA } & $\begin{array}{c}\text { TOTAL DE } \\
\text { CÓDIGOS }- \\
\text { EMENTAS }\end{array}$ & $\begin{array}{c}\text { TOTAL DE } \\
\text { CÓDIGOS }-\end{array}$ & TOTAL \\
\hline Conhecimento do Tema & $120(26,55 \%)$ & $146(22,71 \%)$ & $266(24,29 \%)$ \\
\hline Conhecimento Pedagógico do Conteúdo & $181(40,04 \%)$ & $290(45,10 \%)$ & $471(43,01 \%)$ \\
\hline Conhecimento Pedagógico Geral & $151(33,41 \%)$ & $207(32,19 \%)$ & $358(32,69 \%)$ \\
\hline TOTAL & $452(100 \%)$ & $643(100 \%)$ & $1095(100 \%)$ \\
\hline
\end{tabular}

Os valores absolutos presentes na tabela são relativos ao total de códigos utilizados nos trechos previamente selecionados e o valor em porcentagem refere-se à proporção do aparecimento de determinado código quando comparado com o total de códigos atribuídos. Com os dados observados no Quadro 6, é possível perceber uma similaridade entre a proporção das citações categorizadas tanto nas ementas quanto nos planos de ensino. Outro aspecto relevante é que a categoria "conhecimento pedagógico do conteúdo", composta por 8 diferentes códigos, apresenta maior assiduidade nos trechos analisados. Dentro dessa categoria, a dimensão mais presente foi a "estratégias instrucionais de tópicos específicos". Alguns dos trechos que representam essa dimensão podem ser vistos a seguir:

Planejamento, desenvolvimento e avaliação de atividades e materiais de ensino específicos da área (Plano de Ensino, U.F. 3.4).

Aplicação de metodologias alternativas e experimentos com abordagem lúdica (Ementa, U.F. 29.1).

A segunda categoria mais representativa foi "conhecimento pedagógico geral", composta por 5 diferentes códigos. A dimensão "alunos e aprendizagem" foi a mais relevante, sendo responsável por cerca de $46 \%$ do total de códigos que constituem essa categoria. Tal dimensão apresenta a abordagem de aspectos relativos ao processo de aprendizagem de maneira geral, como podemos perceber nos exemplos de trechos a seguir:

A formação de conceitos científicos na idade escolar para Vygotsky; Teoria do desenvolvimento proximal; o desenvolvimento infantil na perspectiva sociointerassionista (Plano de Ensino, U.F. 3.4).

Os fundamentos da psicologia cognitiva sobre a aprendizagem e suas implicações para decisões sobre. ensino e para o seu desenvolvimento (Ementa, U.F. 37.1). 
O fato de essa dimensão estar mais presente nos documentos analisados apresenta um indicativo da preocupação no processo de formação dos futuros licenciandos em Pedagogia com o processo de aprendizagem de seus futuros alunos. A categoria "conhecimento do tema" foi a menos representativa e teve como dimensões principais "estrutura sintática das Ciências" e "estrutura substantiva das Ciências", ambas com a mesma representatividade. Essa informação mostra que as duas dimensões são abordadas em conjunto nas disciplinas analisadas, como é exemplificado pelos excertos abaixo:

O que é ciências? Quais são as suas especificidades? Qual a diferença entre a ciência dos cientistas e a ciência da escola? Quais são os cientistas? Por que a educação científica é importante para a formação da cidadania? Panorama geral da área de ciência no século XXI (Plano de Ensino, U.F. 28.6).

Estudo das Ciências Naturais: histórico, objeto de estudo e pressupostos epistemológicos do conhecimento nas ciências naturais (Ementa, U.F. 15).

Apesar de não estar tão presente quanto às demais dimensões que compõem as outras categorias, é possível perceber a existência, em boa parte dos documentos, de algum trecho relacionado à concepção da área de Ciências Naturais e suas especificidades.

\section{Considerações finais}

Sendo a base de conhecimentos para o ensino um conjunto de entendimentos, aptidões e outras características que possibilitam ao professor ensinar, buscou-se desvelar o que está manifesto nas estruturas curriculares dos cursos de Licenciatura em Pedagogia em Universidades Públicas Federais, identificando a base de conhecimentos necessários para o Ensino de Ciências Naturais na Educação Infantil. Partindo das análises realizadas, foi possível propor o modelo apresentado na Figura 4, o qual pode ser pensado como uma expansão do modelo proposto por Carlsen (2002). Apesar de possuírem similaridades, o novo modelo engloba as dimensões que emergiram durante o processo de realização desta pesquisa e apresenta especificidades com relação ao Ensino de Ciências na Educação Infantil. O modelo proposto continua sendo constituído pelo conhecimento do tema, conhecimento pedagógico do conteúdo e conhecimento pedagógico geral. A diferença se encontra nas dimensões constituintes do conhecimento pedagógico geral e do conteúdo.

Ao inserir na base as especificidades relativas ao trabalho com a Educação Infantil, optou-se por desmembrar a dimensão "Ensino na Educação Infantil" nas dimensões "Cuidar e Educar", "História da Educação Infantil no Brasil" e "Concepções de Infância". Tal decisão foi tomada buscando melhor atender as especificidades da primeira etapa da Educação Básica.

A dimensão "Cuidar e Educar" engloba aspectos do ensino e do cuidado como complementares no processo de aprendizagem na Educação Infantil, buscando superar o aspecto assistencialista. As concepções de infância se tornaram um domínio, pois, para trabalhar na Educação Infantil, o professor, antes de tudo, precisa conhecer a criança e o entendimento atual de infância no Brasil. O domínio "História da Educação Infantil no Brasil" foi acrescentado, pois tal aspecto auxiliará o futuro professor a compreender melhor a 
constituição do currículo para essa etapa de ensino e como os documentos oficiais refletem as diferentes visões históricas.

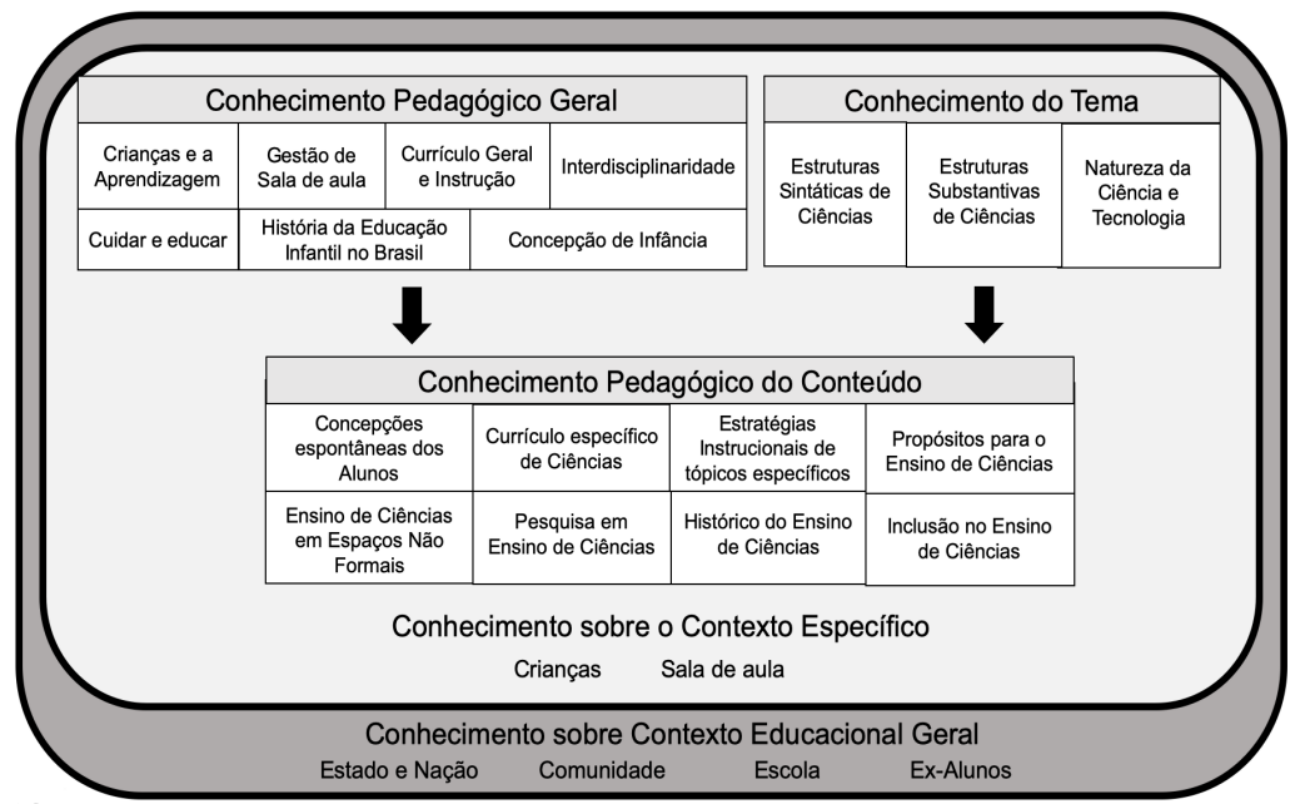

Figura 3 - Base de Conhecimentos para o Ensino de Ciências na Educação Infantil. Fonte: Os autores.

Partindo das ideias aqui descritas, buscou-se trilhar uma alternativa para a formação do futuro licenciando em Pedagogia para atuar com as crianças que frequentam a Educação Infantil, com relação aos conhecimentos da área de Ciências Naturais. Cabe ressaltar aqui que a academia é uma das fontes dos conhecimentos para o ensino, segundo Shulman (1986, 1987, 2014), mas não é a única. Assim, espera-se que essa pesquisa sirva como inspiração para novas investigações sobre a temática da formação do pedagogo com vistas ao trabalho com a área de Ciências Naturais na Educação Infantil. Espera-se, ainda, que tais investigações possibilitem um processo real de mudança nos cursos de Licenciatura em Pedagogia.

\section{Referências}

BARDIN, L. Análise de Conteúdo. São Paulo: Edições 70, 2016. 279p.

BRASIL. Constituição da República Federativa do Brasil de 1988. Brasília, DF: Senado Federal, 5 out. 1988.

BRASIL. Decreto-Lei n01.190, de 4 de abril de 1939: Da organização à Faculdade Nacional de Filosofia. Brasília, DF: Presidência da República. 4 abr. 1939.

BRASIL. Decreto-Lei no 8.530, de 2 de janeiro de 1946. Lei Orgânica de Ensino Normal. Rio de Janeiro: Presidência da República, 2 jan. 1946.

BRASIL. Lei no 9.394, de 20 de dezembro de 1996. Estabelece as diretrizes e bases da educação nacional. Brasília, DF: Presidência da República, 20 dez. 1996.

BRASIL. Ministério da Educação. Base Nacional Comum Curricular: Educação é a base. Brasília, DF: MEC, 2017, 468 p. 
BRASIL. Ministério da Educação. Referencial Curricular Nacional para Educação Infantil. Volume 2 - Formação Pessoal e Social. Brasília: MEC/SEF, 1998.

CAMPOS, M. M.; ROSEMBERG, F.; FERREIRA, I. M. Creches e Pré-Escolas no Brasil. São Paulo: Cortez: Fundação Carlos Chagas, 1993. 134 p.

CARLSEN, W. S. Domains of Teacher Knowledge. In: GESS-NEWSOME, Julie; LEDERMAN, Norman G. (Ed.). Examining Pedagogical Content Knowledge: The Construct and its Implications for Science Education. 2. ed. New York: Kluwer Academic Publishers, 2002. Cap. 5. p. 133-144.

CELLARD, A. A análise documental. In: POUPART, J. et al. A pesquisa qualitativa: Enfoques epistemológicos e metodológicos. Rio de Janeiro: Vozes, 2008. Cap. 7. p. 254-316.

CERISARA, A.B. Educar e cuidar: por onde anda a educação infantil? Perspectiva, Florianópolis, v. 17, n. especial, p. 11-24, jul. / dez. 1999

FERNANDEZ, C. Knowledge base for teaching and pedagogical content knowledge (PCK): some useful models and implications for teachers' training. Problems of Education in the $21^{\text {st }}$ Century, $v$. 60, n. 1, p. 79-100, jul. 2014.

FERNANDEZ, C. Revisitando a base de conhecimentos e o conhecimento pedagógico do conteúdo (pck) de professores de ciências. Revista Ensaio, Belo Horizonte, v. 17, n. 2, p.500-528, maio 2015.

GROSSMAN, P. L. The making of teacher: teacher knowledge and teacher education. New York: Teachers College Press, 1990.

KUHLMANN JUNIOR, M. A Educação Infantil no Século XX. In: STEPHANOU, Maria; BASTOS, Maria Helena Câmara (Org.). Histórias e memórias da educação no Brasil: Vol. III: Século XX. 4. ed. Petrópolis: Vozes, 2005. Cap. 13. p. 182-194.

KUHLMANN JUNIOR, M. Infância e Educação infantil: uma abordagem histórica. 7. ed. Porto Alegre: Mediação, 2015. 192 p.

KUHLMANN JUNIOR, M. Educando a Infância Brasileira. In: LOPES, E. M. T.; FILHO, L. M. F.; VEIGA, C. G. (Org.). 500 anos de educação no Brasil. 5. ed. Belo Horizonte: Autêntica, 2016. p. 469-496.

LÜDKE, M.; ANDRÉ, M. E. D. A. Pesquisa em Educação: abordagens qualitativas. 2. ed. Rio de Janeiro: E.P.U., 2017. 112 p.

MIZUKAMI, M. G. N. Aprendizagem da Docência: algumas contribuições de L. S. Shulman. Educação, Santa Maria, v. 29, n. 2, p. 33-49, jan. 2004.

SAVIANI, D. A pedagogia no Brasil: História e Teoria. 2 ed. Campinas: Autores Associados, 2012. $224 \mathrm{p}$.

SCHEIBE, L. Diretrizes Curriculares para o Curso de Pedagogia: Trajetória Longa e Inconclusa.

Cadernos de Pesquisa, São Paulo, v.37, n.30, p.43-62, jan./abr. 2007.

SHULMAN, L. S. Conhecimentos e Ensino: Fundamentos para uma nova reforma. Cadernos Cenpec, São Paulo, v. 4, n. 2, p.196-229, dez. 2014.

SHULMAN, L. S. These Who Understand: Knowledge in Teaching. Educational Researcher, Thousand Oaks, v. 15, n. 2, p.4-14, fev. 1986.

VIEIRA, L. M. F. Mal necessário: Creches no Departamento Nacional da Criança. Cadernos de Pesquisa, São Paulo, v. 1, n. 67, p.3-16, nov. 1988. 